\title{
Population Pharmacokinetics of Inhaled Fluticasone Furoate and Vilanterol in Subjects with Chronic Obstructive Pulmonary Disease
}

\author{
Sarah Siederer ${ }^{1} \cdot$ Ann $^{\text {Allen }}{ }^{1} \cdot$ Shuying Yang $^{2}$
}

Published online: 16 October 2015

(C) The Author(s) 2015. This article is published with open access at Springerlink.com

\begin{abstract}
Background and Objectives Previous pharmacokinetic studies of the inhaled corticosteroid, fluticasone furoate (FF), and the long-acting, beta2-receptor agonist, vilanterol (VI) have been performed in relatively small populations using non-compartmental pharmacokinetic methods and censored data (due to low drug exposure relative to assay sensitivity). This paper presents a population pharmacokinetic analysis,
\end{abstract}

A. Allen: Deceased, December 2014.

Electronic supplementary material The online version of this article (doi:10.1007/s13318-015-0303-4) contains supplementary material, which is available to authorized users.

Sarah Siederer

Sarah.K.Siederer@gsk.com

1 Clinical Pharmacology Modelling and Simulation Department, GSK, Gunnels Wood Road, Stevenage, Herts SG1 2NY, UK

2 Clinical Pharmacology Modelling and Simulation Department, GSK, Stockley Park West, Uxbridge, Middlesex UB11 1BT, UK utilizing pooled concentration-time data from clinical studies in healthy subjects and from global trials in patients with chronic obstructive pulmonary disease (COPD). The objective of this analysis was to characterize the population pharmacokinetics of FF and VI following once-daily inhalation dosing of FF/VI or the individual components (FF and VI) and to identify significant covariates that impact systemic exposure to FF and VI in this population.

Methods Population pharmacokinetic methods that maximize the likelihood of all data were developed to describe systemic exposure to FF and VI following once-daily FF/VI, FF, or VI, and to identify significant covariates that impact the pharmacokinetics. COPD patients $(N=1225$ for the FF analysis and $N=1091$ for the VI analysis; 94 and $93 \%$ of total data, respectively) and healthy subjects contributed to the analysis.

Results FF data were described by a two-compartment model with first-order absorption and elimination. The population grouping "race" was a significant covariate on inhaled clearance $(\mathrm{CL} / F)$. The area under the curve over $24 \mathrm{~h}\left(\mathrm{AUC}_{0-24}\right)$ for $\mathrm{FF}$ was higher for East Asian, Japanese, and South East Asian (average 23-30 \%) and Asian Central, White Arabic, American Indian/Native Alaskan, and 'other' (10-26\%) subjects compared with White/Caucasians. VI pharmacokinetics were described by a three-compartment model with zero-order absorption and first-order elimination. Significant demographic covariates identified to affect pharmacokinetics of VI were age [on CL/F and central volume $\left(V_{1} / F\right)$ ], bodyweight (on CL/F), sex and smoking (on $V_{1} / F$ ).

Conclusions While significant effects of the covariates were observed in this study, the magnitude of these effects on systemic exposure is not large enough to warrant FF/VI dosage adjustment in patients with COPD. 


\section{Key Points}

Population pharmacokinetic methods that utilize all data including those below the lower limit of quantification were developed to describe fluticasone furoate (FF) and vilanterol (VI) systemic exposure in chronic obstructive pulmonary disease (COPD) patients following once-daily FF/VI, FF, or VI and to identify significant covariates that impact the pharmacokinetics.

Race was a significant covariate on inhaled clearance $(\mathrm{CL} / F)$ of FF resulting in a maximum of $30 \%$ higher in steady-state $\mathrm{AUC}_{0-24}$ for subjects with Asian heritage compared with White/Caucasians. Age, bodyweight, sex and smoking status were significant covariates to affect the pharmacokinetics of VI.

The magnitudes of these covariate effects on systemic exposure are not large enough to warrant FF/VI dosage adjustment in patients with COPD.

\section{Introduction}

Once-daily, combination pharmacological therapies have the potential to simplify treatment in chronic obstructive pulmonary disease (COPD) by reducing dosing frequency whilst increasing compliance [1]. Fluticasone furoate (FF; GW685698), a novel glucocorticoid, in combination with vilanterol (VI; GW642444M), a potent, inhaled, longacting, beta2-receptor agonist (LABA), is approved for the maintenance treatment for COPD as BREO $^{\mathrm{TM}}$ ELLIP$\mathrm{TA}^{\mathrm{TM}}(100 / 25 \mu \mathrm{g})$ in the US and for COPD $(100 / 25 \mu \mathrm{g})$ and asthma $(100 / 25$ and 200/25 $\mu \mathrm{g})$ as RELVAR ${ }^{\mathrm{TM}}$ ELLIPTA $^{\mathrm{TM}}$ in the EU. Fluticasone furoate/vilanterol (FF/VI) is effective at improving lung function in patients with COPD and has a favorable safety and tolerability profile [2, 3]. Furthermore, at therapeutic doses, there is little evidence for the effects of clinical concern previously reported for inhaled corticosteroids (ICSs; decreased serum cortisol) [4, 5] or LABAs (hypokalemia, hyperglycemia, and tachycardia) [6]. However, as with the long-term use of all ICS, there is an increased risk of pneumonia [7].

The pharmacokinetics of FF and VI following administration of FF/VI have been described in healthy subjects [8] as well as in subjects with COPD [2]. Those studies had the limitation that they were conducted in relatively small populations, used non-compartmental pharmacokinetic methods, and pharmacokinetic profiles were censored due to the low systemic exposure to FF and VI relative to assay sensitivity. Appropriate model-based population pharmacokinetic approaches have been developed to address censoring due to non-quantifiable data [9]. Using this methodology and integrating pharmacokinetic concentration-time data from global safety and efficacy studies allowed adequate characterization of the pharmacokinetic profiles and assessment of the influence of potential covariates (demographics, baseline characteristics, and co-administered drugs) as sources of pharmacokinetic variability in the patient population.

This paper presents a population pharmacokinetic analysis utilizing pooled concentration-time data from clinical studies in healthy subjects and global trials in subjects with COPD. Its purpose was to characterize the population pharmacokinetics of FF and VI following oncedaily inhalation dosing of FF/VI or the individual components (FF and VI) to subjects with COPD and identify significant covariates that impact FF and VI systemic exposure in this population.

\section{Methods}

\subsection{Subjects and Study Designs}

Three Phase III (Study 1 [10]; Study 2 [11]; Study 3 [2]) and one Phase II (Study 4 [3]) multicenter, randomized, double-blind, placebo-controlled studies in subjects with COPD were included in the VI meta-analysis (Online Resource: Table S1). The three Phase III studies (Studies 1,2 , and 3 ) in subjects with COPD were also included in the FF meta-analysis. The Phase II study (Study 4) was not included since there was limited informative data (only $0-4 \mathrm{~h}$ post-dose) defining the pharmacokinetic profile of FF. The demographics of the subjects with COPD were generally similar in each study, enabling the data to be combined for the meta-analysis. A further Phase I randomized, placebo-controlled investigation (Study 5 [12]), with intense pharmacokinetic sampling in healthy subjects, was included in both meta-analyses to support population pharmacokinetic modeling and stabilize parameter estimation (Online Resource: Table S1). This Phase I study was chosen because it included both a therapeutic $(200 / 25 \mu \mathrm{g})$ and a supratherapeutic FF/VI dose $(800 / 100 \mu \mathrm{g})$ that provided robust pharmacokinetic data describing the pharmacokinetic profiles for FF and VI. In all five studies FF/VI, FF or VI was administered once daily in the morning.

In Studies 1 and 2, eligible subjects were randomized $(1: 1: 1: 1: 1)$ or $(1: 1: 1: 1: 1: 1)$ to one of the possible treatments (FF/VI: $50 / 25$ or $100 / 25 \mu \mathrm{g}$ Study $1,100 / 25$ or $200 / 25 \mu \mathrm{g}$ Study 2; FF: $100 \mu \mathrm{g}$ Study 1, 100 or $200 \mu \mathrm{g}$ Study 2; VI monotherapy $(25 \mu \mathrm{g})$; or placebo; Online Resource: Table S1). The planned duration of treatment was 24 weeks. In Study 3, eligible subjects were randomized to 
two of the possible three $(50 / 25,100 / 25,200 / 25 \mu \mathrm{g}) \mathrm{FF} / \mathrm{VI}$ strengths and placebo for 4 weeks (Online Resource: Table S1). In study 4, eligible subjects were randomized (2:1) to one of the two possible treatments (FF/VI $400 / 25 \mu \mathrm{g}$ or placebo; Online Resource: Table S1) for 4 weeks. Study 5 was a randomized four-way cross-over study in which eligible healthy subjects received FF/VI 200/25 $\mu \mathrm{g}$, FF/VI 800/100 $\mu \mathrm{g}$, or placebo for 1 week with a placebo tablet administered on Day 7 and placebo for 1 week with a moxifloxacin single dose on Day 7 (Online Resource: Table S1). All blinded study medication was delivered via the ELLIPTA ${ }^{\mathrm{TM}}$ dry powder inhaler (DPI).

In the Phase II and III studies, eligible subjects (aged $\geq 40$ years) had a documented clinical history of COPD and a current or prior history of $\geq 10$ pack-years of cigarette smoking at screening. The Phase I study (Study 5) included healthy, male or female subjects (aged 18-65 years).

All subjects gave written informed consent prior to any study-related procedures and the protocols were approved by the appropriate institutional review boards and conducted in accordance with good clinical practice guidelines and the Declaration of Helsinki.

\subsection{Pharmacokinetic Sample Collection and Bioanalysis}

In each investigation, pharmacokinetic samples were collected for the determination of FF and/or VI plasma concentrations. Samples were collected at nominal times relative to the proposed time of FF/VI, FF or VI administration as outlined in Table S1 (Online Resource). An intense sampling approach was utilized in three of the five studies (Studies 3,4, and 5). The larger Phase III studies (Studies 1 and 2) had sparse pharmacokinetic samples collected pre-dose and within specific collection windows up to $4 \mathrm{~h}$ post-dose (Online Resource: Table S1). Actual times were recorded and used in the population pharmacokinetic analysis.

Plasma samples ( $150 \mu \mathrm{L}$ aliquot) from all studies were analyzed for FF by solid phase extraction using $\left[{ }^{13} \mathrm{C}^{2} \mathrm{H}_{3}\right]-$ GW685698 (FF, as internal standard) followed by highperformance liquid chromatography with tandem mass spectrometry using an Applied Biosystems API-5000. A gradient system using $5 \mathrm{mM}$ ammonium formate and methanol was run with column ACE $50 \times 2.1 \mathrm{~mm}$, C18 $3 \mu \mathrm{m}$, Hichrom Ltd (Reading, Berkshire, UK) running at $45{ }^{\circ} \mathrm{C}$. The ion transition for FF was $m / z$ 539-313. The validation range of the assay was $10-1000 \mathrm{pg} / \mathrm{mL}$ for FF. Within-run precision, between-run precision, and bias were all $\leq 14.3 \%$ over the assay range; the lower limit of quantification for $\mathrm{FF}$ was $10 \mathrm{pg} / \mathrm{mL}$.

Plasma samples ( $200 \mu \mathrm{L}$ aliquot) from all studies were analyzed for VI by solid phase extraction using $\left(\left[{ }^{2} \mathrm{H}_{12}\right]\right.$ GW642444 [VI] as internal standard) followed by high- performance liquid chromatography with tandem mass spectrometry (Applied Biosystems API-5000, Paisley, Renfrewshire, UK). A gradient system using $10 \mathrm{mM}$ ammonium formate containing $0.1 \%$ formic acid and acetonitrile containing $0.1 \%$ formic acid was run with column $50 \times 2.1 \mathrm{~mm}$ i.d. Hypersil Gold, $3 \mu \mathrm{m}$, Thermo Scientific running at $50{ }^{\circ} \mathrm{C}$. The ion transition for VI was $\mathrm{m} / \mathrm{z}$ 486-159. The validation range of the assay was $10-10,000 \mathrm{pg} / \mathrm{mL}$ for VI. Within-run precision, betweenrun precision, and bias were all $\leq 14.4 \%$ over the assay range; the lower limit of quantification for VI was $10 \mathrm{pg} / \mathrm{mL}$. In Study 3, the VI aliquots for analysis were smaller than planned. As a consequence, VI samples were diluted 1 in 2 for analysis, with the result that the VI lower limit of quantification (LLQ) for this study was raised to $20 \mathrm{pg} / \mathrm{mL}$.

Where reported concentrations were above the higher limit of quantification, the plasma samples were diluted (plasma), as appropriate, prior to re-analysis to provide concentrations within the validated range. Quality controls prepared at three different concentrations were analyzed with each batch of samples against separately prepared calibration standards to assess the day-to-day performance of the assay. Quality control results from this study met the acceptance criteria of no more than one-third of the quality control results deviating from the nominal concentration by more than $15 \%$, with at least one quality control result acceptable at each concentration.

\subsection{Population Modeling}

All data preparation and presentations were performed using $\mathrm{R}^{\circledR}$ (Version 2.10.1 or above) [13]. The FF and VI concentration-time data were modeled independently. Nonlinear mixed-effects modeling of the data was conducted using NONMEM version 7.1.2 (ICON Development Solutions, Dublin, Leinster, Ireland [14]). The method selected for minimization was Stochastic Approximation Expectation Maximization (SAEM) with interaction for both the FF and VI analyses. A high proportion of records reporting both $\mathrm{FF}$ and VI concentrations were below the LLQ (10 or $20 \mathrm{pg} / \mathrm{mL}$ ) particularly at the lower doses of FF in the Phase III studies and beyond $2 \mathrm{~h}$ postdose following VI. Given this and the sparse nature of sampling, addition of more extensively sampled concentration-time data from a FF/VI study in healthy subjects (Study 5) at a higher dose $(800 / 100 \mu \mathrm{g})$ and also the highest Phase III dose $(200 / 25 \mu \mathrm{g})$ was essential to achieve an appropriate structural model to describe the data. To incorporate the large extent of non-quantifiable data in each dataset, the methodology that maximized the likelihood for all the data, treating those data below the LLQ (BLQ) as censored was applied. The data were analyzed using the 
methodology referred to as M3 and the F_FLAG option and PHI function available in NONMEM v7.1.2 [9]. Proportional and exponential models were evaluated to describe the inter-individual variability.

Supporting application interfaces for data handling, exploratory diagnostics, and simulation included Xpose V4 [15], $\mathbf{R}^{\circledR}$ (2.10.1 or above) [13] and WinNonlin 5.2 (Pharsight, Mountain View, CA, USA).

\subsubsection{Covariate Analysis}

Covariates were considered only for pharmacokinetic parameters for which it was plausible that a covariate can affect that parameter. Covariates were considered significant if there was a reduction on the objective function value $(\mathrm{OFV})\left[\geq 6.64, \chi^{2}<0.01\right.$ for 1 degree of freedom $(d f)]$, a smaller AIC and there was no overlap in the $95 \%$ confidence interval (CI) for the covariate effect $\left(\theta_{\text {cov }}\right)$.

The covariates considered for evaluation of their influence on FF and VI pharmacokinetics included population (healthy subjects or subjects with COPD), age, weight, height, sex, ethnicity (hispanic or latino/non-hispanic or nonlatino), body mass index, race, tobacco use (number of packyears), smoking status at screening (former or current), reversibility at screening (reversible or non-reversible), and percentage predicted forced expiratory volume in the first second (PFEV). Due to limited numbers of subjects in some of the specific race categories, subjects were grouped and categorized as 'RACE1' as follows: RACE1 $=1-$ White Caucasian ( $82 \%$ of the FF and VI dataset); RACE1 $=2-$ East Asian, Japanese, and South East Asian (14\% of the FF and $13 \%$ of the VI dataset); RACE1 = 3-African American $(3 \%$ of the FF and VI dataset); RACE1 = 4-Asian Central, White Arabic, American Indian/Native Alaskan, and 'other' ( $2 \%$ of the FF and VI dataset).

All five studies included in the meta-analysis for VI used the same assay method, administered the same dose of VI $(25 \mu \mathrm{g})$ and had comparable pharmacokinetic sampling and patient populations. However, there was a suggestion on the review of the raw concentration-time data that VI systemic exposure in study 3 was higher and the study differences had been previously observed (unpublished data; GSK, UK). As a result, 'study' was also included as a covariate to describe these differences.

Plots of inter-individual variability (ETA) versus each covariate were initially used to select potential covariates for inclusion in the FF pharmacokinetic model and the VI pharmacokinetic model.

For FF, each potentially significant covariate identified from the plots was individually included on the fixed parameter in the base model to identify significant covariates. Next, all significant covariates were added to the base model. After the full model had been defined, the significance of each covariate was tested individually by removing one at a time from the full model. A covariate was retained in the model if, upon removal, the OFV increased by more than 6.64 points $\left(\chi^{2}<0.01\right.$ for $\left.1 d f\right)$. The elimination steps were repeated until all non-significant covariates were excluded and the final model was defined.

For VI, potential parameter-covariate relationships were also tested using a step-wise approach, however, because of the long computational time, the influence of a covariate on more than one parameter [such as inhaled clearance $(\mathrm{CL} / F)$ and volume of central compartment $\left.\left(V_{1} / F\right)\right]$ or the effect of multiple covariates (such as smoking and sex) were examined within a single step. Plots of ETA versus each covariate for each intermediate base model were then used to select additional meaningful covariates for inclusion in the VI pharmacokinetic model. This process (including addition of multiple covariates within one step) was repeated for intermediate base models until there were no further meaningful covariates to be selected from the covariate plots. The resulting model was considered to be the final model.

\subsection{Model Evaluation}

The model improvement was evaluated based on goodnessof-fit criteria such as reduction in the objective function value $(\mathrm{OFV})$ of $\geq 6.64, \chi^{2}<0.01$ for $1 d f$, the agreement between the observed and predicted concentration values, and the reduction in pattern of conditional weighted residuals. Precision of parameter estimates, scientific plausibility of parameter estimates, OFV and number of estimated parameters (Akaike criteria), and decrease in the inter-individual and/or residual error were also considered. To evaluate the adequacy of the final models, including the effects of statistically significant covariates, a visual predictive check procedure [16] was performed. This procedure was conducted as follows: 1000 replicates for the FF original dataset and 200 replicates for the original VI dataset were simulated based on the parameter estimates from the final model, and a $95 \%$ prediction interval was computed based on the simulated datasets. The observed plasma concentration-time data were plotted on the prediction interval to visually assess the concordance between the simulated and observed data. In addition, the observed proportion of the data BLQ was plotted with the model prediction interval for proportion of the BLQ data to visually assess the concordance between the simulated and observed BLQ data.

\subsection{Model Predicted Systemic Exposure}

Individual post hoc estimates of CL/F from the final population pharmacokinetic models were used to derive individual $\mathrm{AUC}_{0-24}$ values (ratio of nominal dose/individual post hoc estimate of $\mathrm{CL} / F$ ). Concentration-time profiles 
were simulated using the parameter estimates from the final pharmacokinetic models to provide estimates of $C_{\max }$ for each subject.

\section{Results}

\subsection{Fluticasone Furoate}

\subsubsection{Subject Demographics and Plasma Concentrations}

The demographic characteristics of the subjects included in the FF analysis are summarized in Table S2 (Online Resource). A total of 1307 subjects (healthy subjects or subjects with COPD) were included in the FF pharmacokinetic dataset. The vast majority $(94 \%)$ were subjects with COPD. In total, there were 11,789 observations of which $39 \%$ were reported as BLQ $(<10 \mathrm{pg} / \mathrm{mL})$. Scatter plots of observed FF concentrations relative to the time of the last dose are presented by treatment in Fig. S1 (Online Resource). FF could be quantified $(>10 \mathrm{pg} / \mathrm{mL})$ in the majority ( $\geq 53 \%$ ) of samples collected up to $6 \mathrm{~h}$ post-dose (FF 100 and $200 \mu \mathrm{g}$ and FF/VI 100/25 and 200/25 $\mu \mathrm{g}$ ). Beyond $6 \mathrm{~h}$ post-administration, there was limited FF concentration data in subjects with COPD. Trough (predose) FF concentrations were BLQ in the majority ( $>58 \%$ ) of samples. Following FF/VI 50/25 $\mu \mathrm{g}$ to subjects with COPD, the majority ( $72 \%$ ) of samples were BLQ. FF was quantifiable in the majority of healthy subjects at all timepoints after both FF/VI 200/25 and 800/100 $\mu \mathrm{g}$.

\subsubsection{Fluticasone Furoate Pharmacokinetic Model}

The pharmacokinetics of FF were well described by a twocompartment model with first-order absorption and firstorder elimination (ADVAN4, TRANS4). Due to the very high proportion of non-quantifiable data for $50 / 25 \mu \mathrm{g}$, this treatment was excluded from the model building process after initial runs were unsuccessful. Once the final model was obtained, this model and the base model were re-run including all treatments. For the structural base model, the volume of the central compartment $\left(V_{2} / F\right)$ was fixed to a value appropriate for central $V_{2}(1.36 \mathrm{~L})$ following evaluation of a range of values (unpublished data, GSK, UK, 2012) and the residual error model was additive.

The only covariate found to be significant was "race" on inhaled clearance $(\mathrm{CL} / F)$. The relationship between $\mathrm{CL} / F$ and the categorical covariate RACE1 (COV) was described using the following model:

$\operatorname{Ln} \theta=\theta_{1}+\mathrm{COV}$

where $\theta$ was the population estimate and $\theta_{1}$ was the population estimate for $\mathrm{RACE} 1=1$ and "COV" was the fixed-effect parameter for each "race" category (RACE1 = 1-White; RACE1 = 2-East Asian, Japanese and South East Asian; RACE1 = 3-African American; RACE1 $=4$-Asian Central, White Arabic, American Indian/Native Alaskan and 'other').

The parameter estimates for the final model are presented in Table 1 . The majority of fixed-effect parameters (THETAs) were estimated with reasonable precision $(<30 \%)$. The fixed-effect parameters RACE1 $=3$ and $\mathrm{RACE} 1=4$ on $\mathrm{CL} / F$ were estimated with less precision [\% relative standard error (RSE) $199 \%$ for RACE1 $=3$ and $51 \%$ for RACE1 = 4). However, it should be noted that RACE1 $=3$ and RACE1 $=4$ groups represented a small proportion of the total population $(\leq 3 \%)$ of the FF dataset. Inter-individual variances (exponential model) were estimated with reasonable precision ( $\%$ RSE $\leq 36 \%$ ). An additive error model described the residual variability.

The typical value of $\mathrm{CL} / F$ was $230 \mathrm{~L} / \mathrm{h}$ for a white Caucasian subject with COPD. In comparison, CL/F was lower in subjects categorized as RACE1 $=2$ (East Asian, Japanese, and South East Asian) and RACE1 = 4 (Asian Central, White Arabic, American Indian/Native Alaskan, and 'other') (186 and $176 \mathrm{~L} / \mathrm{h}$, respectively) and slightly higher $(244 \mathrm{~L} / \mathrm{h})$ for subjects categorized as RACE1 $=3$ (African American), although it should be noted that the fixed-effect parameter RACE1 $=3$ was estimated with less precision (\%RSE 199\%) and should thus be interpreted with caution.

\subsubsection{Fluticasone Furoate Model Evaluation}

The goodness-of-fit of the final model for FF, including records from the 50/25 $\mu \mathrm{g}$ dose, was assessed by a graphical approach (Fig. 1). The visual predictive checks for the FF final model showed that the majority of the data were captured within the prediction interval that encompasses $90 \%$ of the population as indicated by the 5 th and 95th percentiles (Fig. 2). The models also generally described the proportion of BLQ data (Fig. 2).

\subsection{Vilanterol}

\subsubsection{Subject Demographics and Plasma Concentrations}

The demographic characteristics of the subjects included in the VI meta-analysis are summarized in Table S2 (Online Resource). A total of 1167 subjects (healthy subjects or subjects with COPD) were included in the VI pharmacokinetic dataset. The vast majority $(94 \%)$ were subjects with COPD. In total, there were 10,807 observations of which $30 \%$ were reported as BLQ $(\leq 20 \mathrm{pg} / \mathrm{mL})$. Scatter plots of observed VI concentrations relative to the time of the last dose are presented by treatment in Fig. S1 (Online 
Table 1 Final fluticasone furoate pharmacokinetic model: log-transformed and untransformed parameter estimates

\begin{tabular}{llll}
\hline Parameter & Ln estimate $(95 \% \mathrm{CI})$ & Estimate $(95 \% \mathrm{CI})$ & RSE $(\%)$ \\
\hline $\mathrm{CL} / F(\mathrm{~L} / \mathrm{h})$ & $5.44(5.39,5.49)$ & $230(219,242)$ & 0.47 \\
$V_{2} / F(\mathrm{~L})$ & 0.31 FIXED & 1.36 FIXED & FIXED \\
$Q / F(\mathrm{~L} / \mathrm{h})$ & $5.59(5.40,5.78)$ & $268(221,324)$ & 1.73 \\
$V_{3} / F(\mathrm{~L})$ & $4.71(4.51,4.91)$ & $111(90.9,136)$ & 2.21 \\
$k_{\mathrm{a}}\left(\mathrm{h}^{-1}\right)$ & $-2.95(-3.01,-2.89)$ & $0.0523(0.0493,0.0556)$ & 1.06 \\
$\mathrm{RACE} 1=2$ on $\mathrm{CL} / F$ & $-0.211(-0.329,-0.0930)$ & $0.810(0.720,0.911)$ & 28.5 \\
$\mathrm{RACE} 1=3$ on CL/F & $0.0602(-0.175,0.295)$ & $1.062(0.839,1.343)$ & 199.0 \\
$\mathrm{RACE} 1=4$ on CL/F & $-0.265(-0.528,-0.002)$ & $0.767(0.590,0.998)$ & 50.6 \\
\hline
\end{tabular}

$C I$ confidence interval, $R S E$ relative standard error, $C L / F$ inhaled clearance, $V_{2} / F$ volume of central compartment, $Q / F$ intercompartmental clearances, $V_{3} / F$ volumes of peripheral compartment, $k_{a}$ absorption rate

RACE1 = 2-East Asian, Japanese, and South Asian; RACE1 = 3-African American; RACE1 = 4 Asian Central, White Arabic, American Indian/Native Alaskan, and other
Fig. 1 Goodness-of-fit plots for the fluticasone furoate final model in subjects with COPD (solid line is the line of identity as a reference and the dashed line is the loess smooth). COPD chronic obstructive pulmonary disease, $F F$ fluticasone furoate
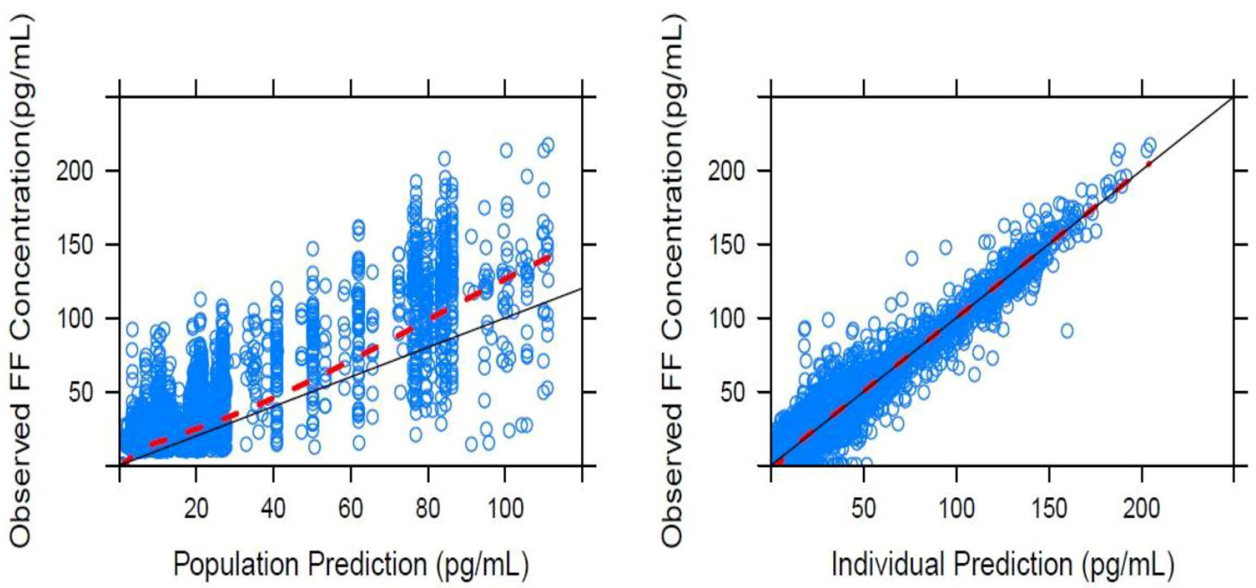

Resource). Where the VI LLQ was $10 \mathrm{pg} / \mathrm{mL}$ (Studies 1, 2, and 3), VI could be quantified in the majority ( $\geq 81 \%$ ) of samples up to $4 \mathrm{~h}$ post-dose (i.e., last sampling time/window) following administration to subjects with COPD. Reflecting the higher LLQ (20 pg/mL) in Study 4, VI plasma concentrations were BLQ in the majority ( $\geq 53 \%$ ) of samples by $3 \mathrm{~h}$ post-dose and in $\geq 84 \%$ of samples by $6 \mathrm{~h}$ after dosing. Overall, there was very limited VI concentration-time data defining the VI pharmacokinetic profile in subjects with COPD beyond $4 \mathrm{~h}$ post-administration. Following FF/VI $(200 / 25 \mu \mathrm{g})$ to healthy subjects $\geq 50 \%$ of samples were BLQ by $2 \mathrm{~h}$ post-dose. At the fourfold higher VI dose (FF/VI; 800/100 $\mu \mathrm{g}$ ), profiles were well defined with $\geq 68 \%$ of the samples having quantifiable concentrations of VI at trough.

\subsubsection{Vilanterol Pharmacokinetic Model}

VI concentration-time profiles reflected rapid attainment of VI $C_{\max }$ following oral inhalation but provided little data to define the absorption phase (Online Resource: Fig. S1). Whilst first-order absorption models were explored, using intense sampling concentration-time profiles from healthy subjects, zero-order absorption appeared to better describe the data. Based on the observed concentration-time profiles, and initial model building, a three-compartment linear model with zero-order absorption and first-order elimination was found to adequately describe the data (ADVAN11, TRANS4). For the structural base model, $\mathrm{CL} / F, V_{1} / F$, volume of the peripheral compartment $\left(V_{2} / F\right)$, and residual error were separated by population (subjects with COPD or healthy subjects); inter-subject variability on $D_{1}, Q_{2} / F$, and $V_{2} / F$ was fixed and residual error was additive.

The final population pharmacokinetic model incorporated the effect of age, weight, and study (Study 4) on $\mathrm{CL} / F$ and age, smoking, sex, and study (Studies 3 and 4 ) on $V_{1} / F$ for subjects with COPD.

The effect of a categorical covariate [e.g., sex (males $=1$, females $=2$ )] was evaluated for its influence on the population mean values as follows: 
a

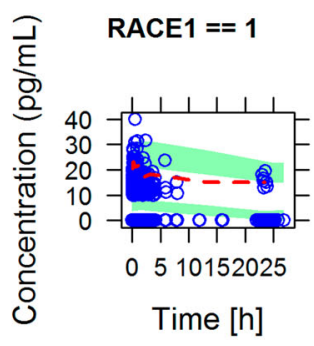

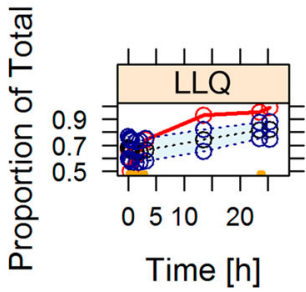

b

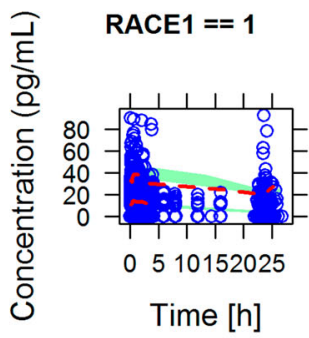

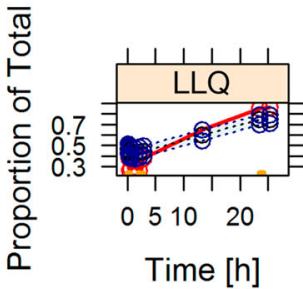

C
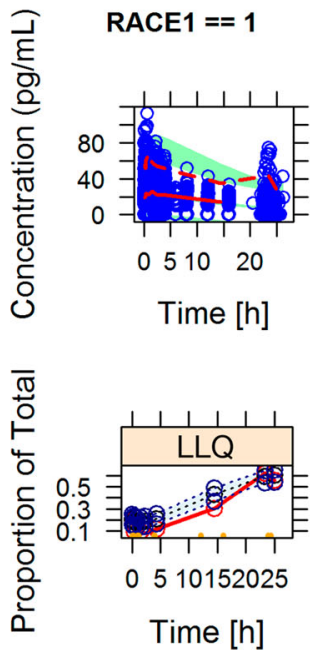

Fig. 2 Visual predictive check plots stratified by dose regimen $(\mathbf{a}=50 \mu \mathrm{g}, \mathbf{b}=100 \mu \mathrm{g}$, and $\mathbf{c}=200 \mu \mathrm{g})$ for the final fluticasone furoate model; concentration versus time [observed median (dashed line), prediction intervals for median, 5th and 95th percentiles (shaded areas)] and the proportion of BLQ values by time [observed median (dashed line), prediction intervals for median, 5th and 95th
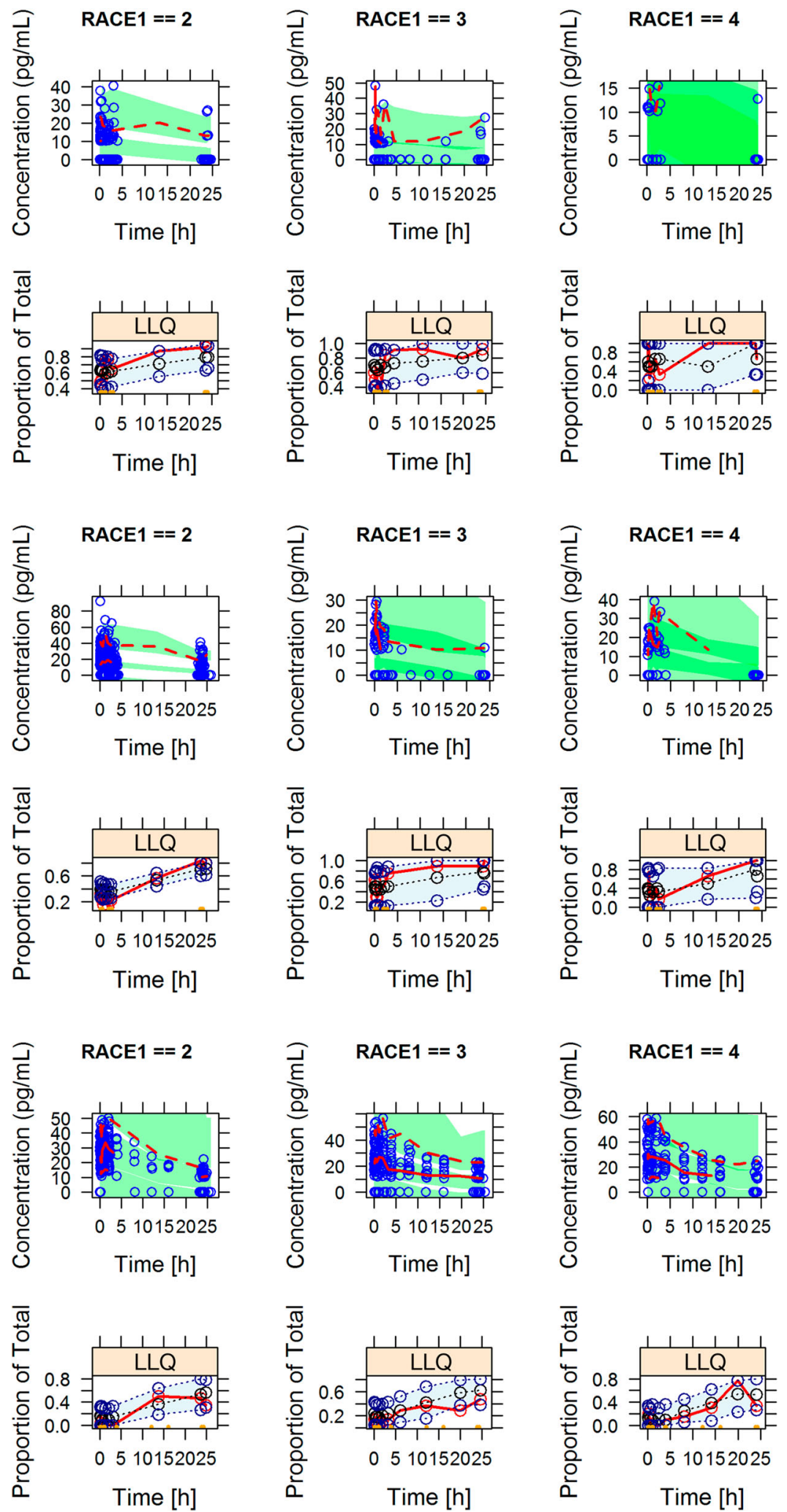

percentiles (shaded areas)]. $B L Q$ below the lower limit of quantification, $L L Q$ lower limit of quantification, $R A C E 1=1$ White Caucasian, $R A C E 1=2$ East Asian, Japanese, and South East Asian, $R A C E 1=3$ African American, RACE1 = 4 Asian Central, White Arabic, American Indian/Native Alaskan, and other 
$\mathrm{LnCL}=\theta_{1}+\theta_{\mathrm{COV}} \times($ covariate -1$)$.

The effect of a continuous covariate (e.g., weight) was evaluated for its influence on the population mean values as follows:

$\mathrm{LnCL}=\theta_{1}+\theta_{\mathrm{COV}} \times($ covariate -1$)$.

The parameter estimates for the final model are presented in Table 2. The majority of fixed-effect parameters (THETAs) were estimated with reasonable precision $(<27 \%)$. The fixed-effect parameters, age, sex, and study on $V_{1} / F$, were estimated with less precision (\%RSE 35-48 \%). Inter-individual variances (exponential model) were estimated with reasonable precision ( $\% \mathrm{RSE} \leq 25 \%)$, with exception of ETA on volume of the peripheral compartment $\left(V_{3} / F\right)$ where \%RSE was $64 \%$. An additive error model described the residual variability.

The typical value of $\mathrm{CL} / F$ was $94.6 \mathrm{~L} / \mathrm{h}$ for a subject with COPD (aged 60 years and weighing $70 \mathrm{~kg}$ ) within the Phase III studies (Studies 1, 2, and 3). For these subjects, there was a decrease $(27 \%)$ in $C L / F$ over the observed age (range 41-84 years), and a reduction (47\%) in inhaled clearance is also predicted with decreasing bodyweight (range of $160-35 \mathrm{~kg})$. In Study 4, the typical value of CL/F (59.4 L/h) was predicted to be lower (37\%; COPD subjects aged 60 years and weighing $70 \mathrm{~kg}$ ) and the predicted decrease in $\mathrm{CL} / F$ with decreasing body weight or increasing age (47 and $27 \%$, respectively) was consistent with that predicted for the Phase III studies (Studies 1, 2, and 3).
For $V_{1} / F$, age, sex, smoking, and study (Studies 3 and 4) are significant covariates for subjects with COPD. The central volume $\left(V_{1} / F\right)$ was found to decrease $(30 \%)$ with increasing age (41-84 years), to be lower (12\%) in females, and to be increased with smoking (34\%). The typical value for $V_{1} / F$ (non-smoking male, aged 60 years) is predicted to be $639 \mathrm{~L}$ (Studies 1 and 2), $447 \mathrm{~L}$ (Study 3) and $185 \mathrm{~L}$ (Study 4).

\subsubsection{Vilanterol Model Evaluation}

The goodness-of-fit of the final model for VI was assessed by a graphical approach (Fig. 3). The visual predictive checks for the VI model showed that the majority of the data were captured within the prediction interval that encompasses $90 \%$ of the population as indicated by the 5th and 95th percentiles (Fig. 4). The models also generally described the proportion of BLQ data (Fig. 4), although there was a trend to underpredict the proportion of VI BLQ data at early timepoints $(<2 \mathrm{~h}$ post-dose $)$ in Studies 1, 2, and 4 .

\section{Discussion}

A two-compartment model with first-order absorption and first-order elimination described the pharmacokinetics of FF following inhaled administration via ELLIPTA ${ }^{\mathrm{TM}}$ DPI
Table 2 Final vilanterol pharmacokinetic model: logtransformed and untransformed parameter estimates

\begin{tabular}{|c|c|c|c|}
\hline Parameter & Ln estimate (95\% CI) & Estimate $(95 \% \mathrm{CI})$ & RSE $(\%)$ \\
\hline $\mathrm{CL} / F, \mathrm{HVT}(\mathrm{L} / \mathrm{h})$ & $4.91(4.81,5.01)$ & $135.6(122.7,149.9)$ & 1.06 \\
\hline $\mathrm{CL} / F, \mathrm{COPD}(\mathrm{L} / \mathrm{h})$ & $4.55(4.51,4.59)$ & $94.6(90.9,98.5)$ & 0.41 \\
\hline Study 4 on $\mathrm{CL} / F$, COPD & $-0.465(-0.633,-0.297)$ & $0.628(0.531,0.743)$ & 18.5 \\
\hline Age on $\mathrm{CL} / F, \mathrm{COPD}$ & $-0.433(-0.660,-0.206)$ & $0.649(0.517,0.814)$ & 26.8 \\
\hline Wt on $\mathrm{CL} / F, \mathrm{COPD}$ & $0.421(0.286,0.556)$ & $1.52(1.33,1.74)$ & 16.4 \\
\hline$V_{1} / F$, HVT (L) & $5.07(4.97,5.17)$ & $159.2(144.0,175.9)$ & 0.99 \\
\hline$V_{1} / F, \operatorname{COPD}(\mathrm{L})$ & $6.46(6.37,6.55)$ & $639.0(584.1,699.2)$ & 0.74 \\
\hline Study 4 on $V_{1} / F$, COPD & $-1.24(-1.51,-0.968)$ & $0.289(0.221,0.380)$ & 11.2 \\
\hline Age on $V_{1} / F$, COPD & $-0.499(-0.911,-0.087)$ & $0.607(0.402,0.917)$ & 42.1 \\
\hline Smoking on $V_{1} / F$, COPD & $0.295(0.179,0.411)$ & $1.34(1.20,1.51)$ & 20.1 \\
\hline Sex on $V_{1} / F$, COPD & $-0.128(-0.25,-0.006)$ & $0.880(0.779,0.994)$ & 48.4 \\
\hline Study 3 on $V_{1} / F$, COPD & $-0.358(-0.601,-0.115)$ & $0.699(0.548,0.891)$ & 34.6 \\
\hline$Q_{2} / F(\mathrm{~L} / \mathrm{h})$ & $5.49(5.39,5.59)$ & $242.3(219.2,267.7)$ & 0.94 \\
\hline$V_{2} / F, \operatorname{HVT}(\mathrm{L})$ & $6.23(6.03,6.43)$ & $507.8(415.7,620.2)$ & 1.65 \\
\hline$V_{2} / F, \mathrm{COPD}(\mathrm{L})$ & $5.18(5.03,5.33)$ & $177.7(152.9,206.4)$ & 1.52 \\
\hline$Q_{3} / F(\mathrm{~L} / \mathrm{h})$ & $4.95(4.83,5.07)$ & $141.2(125.2,159.2)$ & 1.26 \\
\hline$V_{3} / F(\mathrm{~L} / \mathrm{h})$ & $7.65(7.58,7.72)$ & $2100.6(1958.6,2253.0)$ & 0.43 \\
\hline$D_{1}(\mathrm{~h})$ & $-2.32(-2.39,-2.25)$ & $0.098(0.092,0.105)$ & 1.63 \\
\hline
\end{tabular}

$C I$ confidence interval, $C L / F$ inhaled clearance, $C O P D$ chronic obstructive airways disease, $H V T$ healthy volunteers, $R S E$ relative standard error, $W t$ weight, $V_{l} / F$ volume of central compartment, $Q_{2} / F$ and $Q_{3} / F$, intercompartmental clearances; $V_{2} / F, V_{3} / F$ volumes of peripheral compartment; $D_{1}$ input duration 
Fig. 3 Goodness-of-fit plots for the vilanterol final model in subjects with COPD (solid line is the line of identity as a reference and the dashed line is the loess smooth). COPD chronic obstructive pulmonary disease
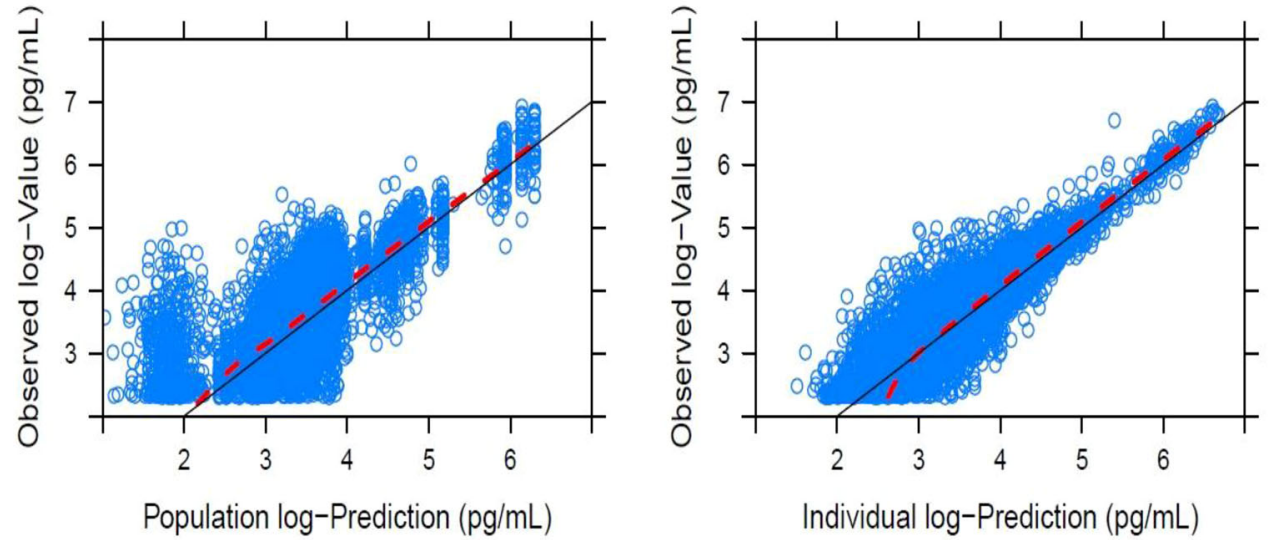

as FF/VI or FF alone. The final pharmacokinetic model was used to derive individual estimates and summary statistics of FF steady-state systemic exposure $\left(C_{\max }\right.$ and $\left.\mathrm{AUC}_{0-24}\right)$ across the COPD population (Table 3). Based on the model predictions, there were no notable differences in FF exposure between individual component (FF) versus combination treatment (FF/VI; Table 3). This finding is consistent with a lack of an effect of combination treatment with FF/VI on FF pharmacokinetics following administration of FF/VI and FF to healthy subjects [8]. For those subjects recruited to the large global Phase III trials, systemic exposure was predicted to increase in an approximately proportional manner with FF dose (either as a monotherapy or as a FF/VI combination treatment; 50/25, $100 / 25$ and $200 / 25 \mu \mathrm{g}$ ) (Table 3). It should be noted that average systemic exposure following a low dose of FF (FF $50 \mu \mathrm{g}$ or FF/VI $50 / 25 \mu \mathrm{g}$ ) is predicted to be BLQ of the analytical assay $(10 \mathrm{pg} / \mathrm{mL})$.

The relevance of the only significant covariate ("race") on FF exposure in patients with COPD was also assessed by simulations of individual steady-state $\mathrm{AUC}_{0-24}$ (Table 3). For East Asian, Japanese, and South East Asian subjects, predicted $\mathrm{FF} \mathrm{AUC}_{0-24}$ was on average 23-30\% higher compared with white Caucasians. This finding is consistent with higher FF systemic exposure seen previously in healthy subjects of East Asian origin following inhaled administration [17]. In the healthy subject study, there was no evidence for a difference in CYP3A4 activity (as measured by both urine cortisol:6- $\beta$-hydroxy cortisol ratio and plasma 4- $\beta$-hydroxy-cholesterol) between Chinese, Japanese and Korean subjects compared with Caucasians [17]. In addition, given the high capacity of the CYP3A4 system and the low clinical dose of FF, any potential differences in enzyme expression would not be anticipated to explain the differences in $\mathrm{CL} / F$. Furthermore, there were no marked differences in the inherent pharmacokinetics of FF following intravenous FF $250 \mu \mathrm{g}$ between ethnic groups, other than those accounted for by body weight differences [17].
Also, FF is not anticipated to be a substrate of anion or cation transporters, and although FF is a substrate of the transporter P-glycoprotein, inter-ethnic differences in activity are not anticipated. Thus, the exact reasons for these differences are not known but could be a consequence of differences in mucociliary clearance, lung solubility, and/or regional lung disposition of inhaled FF. Despite the higher FF systemic exposure for East Asian, Japanese, and South East Asian patients with $\mathrm{COPD}$, the predicted FF $\mathrm{AUC}_{0-24}$ following all FF treatments was below levels $(1000 \mathrm{pg} \cdot \mathrm{h} / \mathrm{mL}$ ) which are considered to be the threshold for significant cortisol suppression (a $20 \%$ reduction) in placebo-controlled studies [18]. For subjects categorized as Asian Central, White Arabic, American Indian/Native Alaskan, and 'other', estimates of $\mathrm{FF} \mathrm{AUC}_{0-24}$ were on average 10-26\% higher compared with white Caucasian subjects although it should be noted that the numbers of subjects in this race category were low at each dose $(<2 \%$ in the FF dataset; Table 3) and the parameters were not well estimated.

A three-compartment model with zero-order absorption and first-order elimination described the pharmacokinetics of VI following inhaled administration via ELLIPTA ${ }^{\mathrm{TM}}$ DPI as FF/VI or VI alone. Due to the fast absorption following inhalation and sampling times specified for pharmacokinetic analysis, a zero-order absorption model was found to be better in terms of model selection compared to a first-order absorption model. However, this was largely data driven.

The final model was used to derive individual estimates and summary statistics of VI steady-state systemic exposure $\left(C_{\max }\right.$ and $\left.\mathrm{AUC}_{0-24}\right)$ across the COPD population (Table 4). Comparison of the model predicted systemic exposure showed no difference between individual component versus combination treatment (Table 4). This is consistent with a lack of an effect of combination treatment on VI pharmacokinetics following administration of FF/VI and VI to healthy subjects [8]. Age, weight, sex, and 


\section{Study 3 (LLQ $20 \mathrm{pg} / \mathrm{mL}$ )}

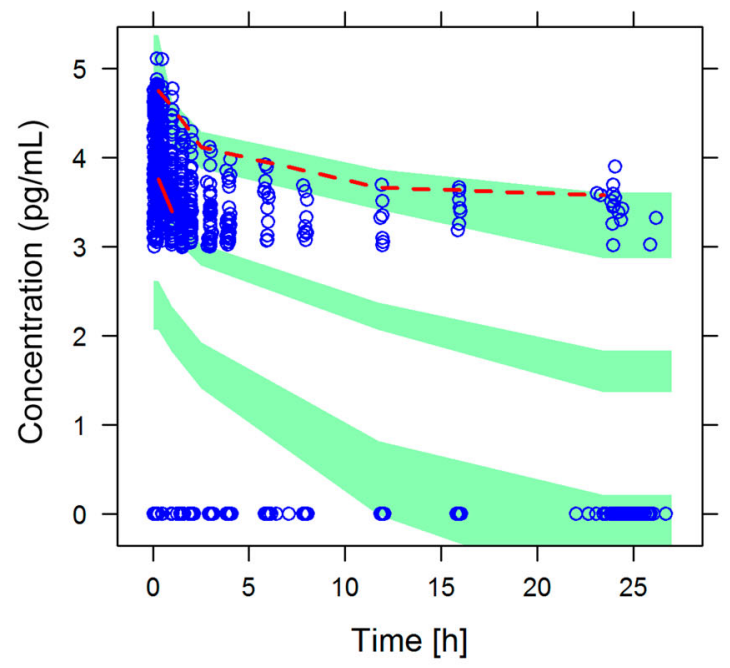

Studies 1, 2 and 4 (LLQ $10 \mathrm{pg} / \mathrm{mL})$

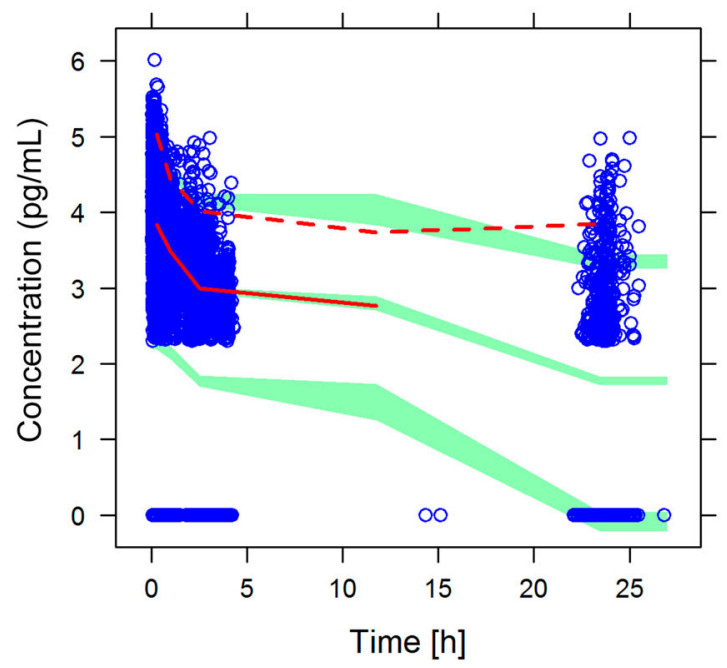

Fig. 4 Visual predictive check plots stratified by study for the final vilanterol model; observation [ $\mathrm{LN}$ concentration $(\mathrm{pg} / \mathrm{mL})$ ] versus time and the proportion of BLQ values by time. Observed median (solid line), 5th, and 95th percentiles (dashed line) and prediction intervals

smoking were significant covariates on the pharmacokinetics of VI in subjects with COPD. However, there appeared to be no notable difference in VI systemic exposure for males compared with females (Table 4) and current smokers were predicted to have only slightly lower AUC $_{(0-24)}$ and $C_{\max }$ compared with former smokers (5 and $22 \%$, respectively; Table 4). Furthermore, there was no notable trend in predicted systemic exposure with increasing age or decreasing bodyweight (Online Resource: Fig. S2). The decrease in $\mathrm{CL} / F$ with age may in part reflect declining renal function in the elderly. Whilst severe renal impairment has no apparent clinically relevant effects on

\section{Study 3 (LLQ $20 \mathrm{pg} / \mathrm{mL}$ )}

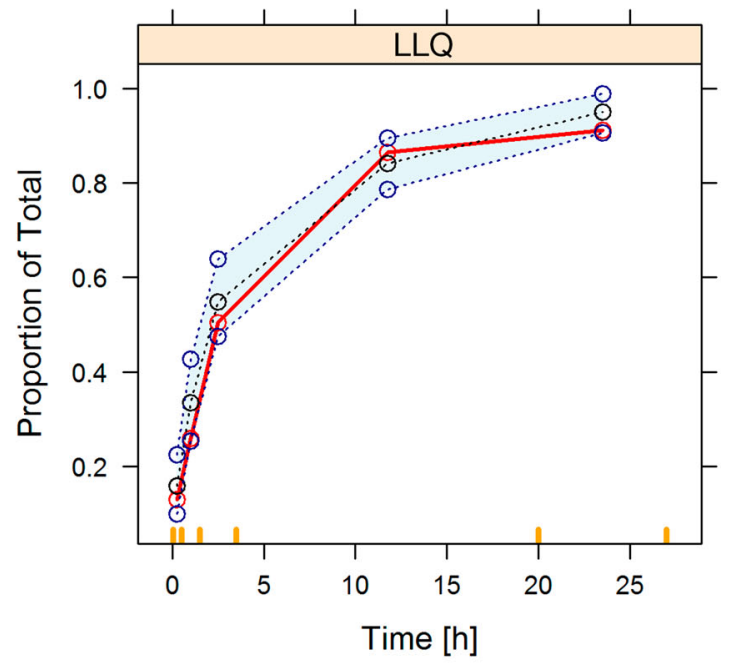

Study 1,2 and 4 (LLQ $10 \mathrm{pg} / \mathrm{mL})$

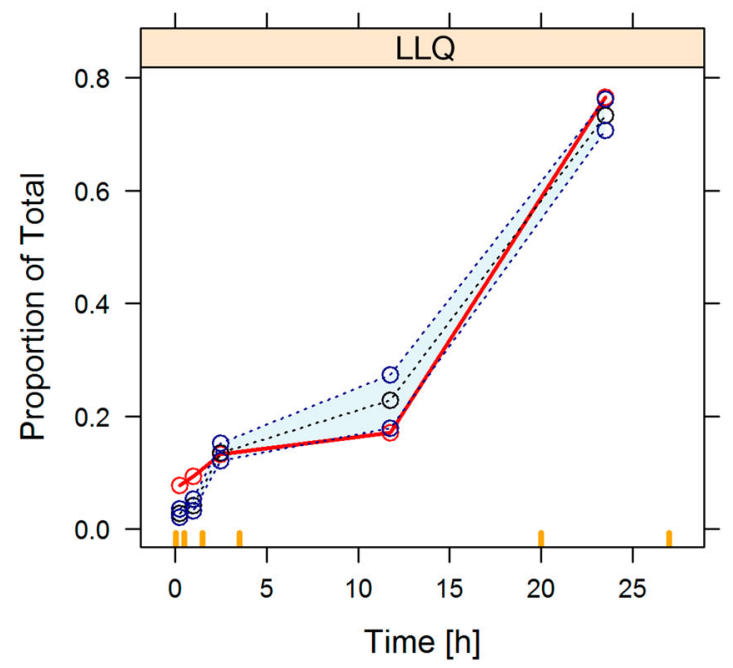

for median, 5th, and 95th percentiles (shaded areas). BLQ below the lower limit of quantification, $L L Q$ lower limit of quantification

the pharmacokinetic or pharmacodynamic properties or tolerability of FF/VI, the ratio of adjusted means (renal impairment/healthy subjects) for $\mathrm{VI} \mathrm{AUC}_{0-24}$ was 1.56 [19], consistent with a small effect of declining renal function on $\mathrm{VI} \mathrm{CL/F}$.

Whilst Studies 3 and 4 were both identified as significant covariates on the pharmacokinetics of VI, the predicted pharmacokinetics of VI was only notably different in the Phase II trial (Study 4; Table 4). As a result of lower $\mathrm{CL} / F$ and a smaller $V_{1} / F$, the VI exposure was predicted to be higher (approximately 1.5-fold higher $\mathrm{AUC}_{0-24}$ and 2.7fold higher $C_{\max }$ ). This Phase II study represented a small 
Table 3 Model predicted systemic exposure [geometric mean $(95 \% \mathrm{CI})$ ] for fluticasone furoate [FF; $C_{\max }$ and $\left.\mathrm{AUC}_{0-24}\right]$ following administration of $\mathrm{FF}$ (as FF/VI or FF) in subjects with COPD (Studies 1, 2, and 3) and predicted $\mathrm{AUC}_{0-24}$ by race category
Table 4 Model predicted systemic exposure [geometric mean $(95 \% \mathrm{CI})]$ for $\mathrm{VI}\left[C_{\max }\right.$ and $\mathrm{AUC}_{0-24}$ ] following $25 \mu \mathrm{g}$ VI (as FF/VI or VI) in subjects with COPD

\begin{tabular}{|c|c|c|c|c|}
\hline Treatment $(\mu \mathrm{g})$ & Population/race & $N$ & $C_{\max }(\mathrm{pg} / \mathrm{mL})$ & $\mathrm{AUC}_{0-24}(\mathrm{pg} \cdot \mathrm{h} / \mathrm{mL})$ \\
\hline $100 / 25$ & COPD & 391 & $11.96(10.94,12.99)$ & $182.15(169.61,194.69)$ \\
\hline $100 \mathrm{FF}$ & COPD & 333 & $11.46(10.54,12.38)$ & $181.44(167.01,195.87)$ \\
\hline $200 / 25$ & COPD & 234 & $20.30(18.41,22.18)$ & $288.02(260.78,315.27)$ \\
\hline $200 \mathrm{FF}$ & COPD & 168 & $23.60(20.83,26.37)$ & $309.58(284.51,334.65)$ \\
\hline \multicolumn{5}{|l|}{$\mathrm{FF}$ dose $\mathrm{e}^{\mathrm{a}}$} \\
\hline 50 & COPD & 231 & $7.52(6.52,8.52)$ & $82.92(75.57,90.28)$ \\
\hline 100 & COPD & 724 & $11.73(11.03,12.43)$ & $181.82(172.61,191.04)$ \\
\hline 200 & COPD & 402 & $21.62(20.02,23.22)$ & $319.69(301.42,337.96)$ \\
\hline \multicolumn{5}{|c|}{$\mathrm{FF}$ dose ${ }^{\mathrm{a}} / \mathrm{RACE} 1^{\mathrm{b}}$} \\
\hline \multirow[t]{4}{*}{50} & 1 & 174 & - & $79.05(71.61,86.49)$ \\
\hline & 2 & 37 & - & $102.77(79.00,126.54)$ \\
\hline & 3 & 16 & - & $81.19(43.13,119.25)$ \\
\hline & 4 & 4 & - & $99.25(75.72,122.77)$ \\
\hline \multirow[t]{4}{*}{100} & 1 & 591 & - & $176.04(165.98,186.10)$ \\
\hline & 2 & 111 & - & $223.04(198.14,247.95)$ \\
\hline & 3 & 13 & - & $128.25(94.85,161.65)$ \\
\hline & 4 & 9 & - & $202.34(140.45,264.24)$ \\
\hline \multirow[t]{4}{*}{200} & 1 & 362 & - & $319.68(299.78,339.58)$ \\
\hline & 2 & 20 & - & $394.61(350.67,438.55)$ \\
\hline & 3 & 17 & - & $245.42(207.09,283.75)$ \\
\hline & 4 & 3 & - & $352.68(248.13,457.23)$ \\
\hline
\end{tabular}

$A U C_{0-24}$ area under the curve during $24 \mathrm{~h}, C_{\max }$ maximum plasma concentration, COPD chronic obstructive pulmonary disease, $F F$ fluticasone furoate, $V I$ vilanterol

a Administered as FF/VI or FF

${ }^{\mathrm{b}}$ RACE1 = 1-White Caucasian; RACE1 = 2-East Asian, Japanese, and South Asian; RACE1 = 3African American; RACE1 = 4-Asian Central, White Arabic, American Indian/Native Alaskan, and other

\begin{tabular}{|c|c|c|c|}
\hline Study & $N$ & $C_{\max }(\mathrm{pg} / \mathrm{mL})$ & $\mathrm{AUC}_{0-24}(\mathrm{pg} \cdot \mathrm{h} / \mathrm{mL})$ \\
\hline All studies ${ }^{\mathrm{a}}$ & 1091 & $43.2(41.8,44.6)$ & $265.7(259.5,271.9)$ \\
\hline HZC112206 (Study 1) & 496 & $43.2(41.4,45.1)$ & $273.7(264.5,283.3)$ \\
\hline HZC112207 (Study 2) & 506 & $39.3(37.5,41.3)$ & $251.1(243.2,259.4)$ \\
\hline HZC110946 (Study 3) & 50 & $49.7(43.4,57.1)$ & $249.2(219.6,282.8)$ \\
\hline HZC111348 (Study 4) & 39 & $120.5(103.8,139.8)$ & $408.2(365.3,456.1)$ \\
\hline \multicolumn{4}{|l|}{ Sex } \\
\hline Female & & $42.1(40.5,43.8)$ & $263.8(256.4,271.4)$ \\
\hline Male & & $45.7(42.9,48.6)$ & $269.8(259.1,281.0)$ \\
\hline \multicolumn{4}{|l|}{ Smoking status } \\
\hline Former & & $49.4(47.0,51.9)$ & $272.8(263.8,282.2)$ \\
\hline Current & & $38.3(36.8,40.0)$ & $259.5(251.3,267.9)$ \\
\hline \multicolumn{4}{|l|}{ Treatment } \\
\hline Vilanterol $^{\mathrm{b}}$ & 714 & $42.3(40.7,44.0)$ & $261.6(254.1,269.0)$ \\
\hline Fluticasone furoate/vilanterol ${ }^{\mathrm{c}}$ & 338 & $40.1(37.9,42.4)$ & $261.2(250.6,272.3)$ \\
\hline
\end{tabular}

$A U C_{0-24}$ area under the curve during $24 \mathrm{~h}, C I$ confidence interval, $C_{\max }$ maximum plasma concentration, $C O P D$ chronic obstructive pulmonary disease, $F F$ fluticasone furoate, $V I$ vilanterol

a All studies (Studies 1, 2, 3 and 4) and FF/VI strengths (50/25, 100/25, 200/25, 400/25 $\mu \mathrm{g}$ )

b $25 \mu \mathrm{g}$ VI

c $200 / 25,100 / 25$ and 50/25 $\mu \mathrm{g}$ FF/VI 
number of subjects $(N=39)$ with COPD compared with the larger Phase III population $(N=1052$ subjects with COPD; Table 4). The timing of the pharmacokinetic sample collection in this Phase II study was almost identical to that for one of the Phase III trials (Study 3). Furthermore, the demographic characteristics in the Phase II study were also consistent with the Phase III population [other than a slightly higher post-albuterol/salbutamol $\mathrm{FEV}_{1} \%$ predicted at screening (58 vs. $46-49 \%$, respectively), a higher $\%$ of subjects who were reversible (51 vs. $24-30 \%$, respectively) and a lower $\%$ of subjects who were current smokers ( 25 vs. $52-84 \%$, respectively)]. The only other difference was that subjects in this study received 400/25 $\mu \mathrm{g}$ FF/VI compared with 50/25, 100/25 or 200/25 $\mu \mathrm{g}$ FF/VI in the Phase III investigations although there is no evidence to suggest that FF affects the pharmacokinetics of VI [8]. Therefore, the reason for this marked study difference is not clear and may just reflect between-study variability. Whilst the systemic exposure was higher in the Phase II trial, the VI $C_{\max }$ values estimated for subjects with COPD (geometric mean $120 \mathrm{pg} / \mathrm{mL}$ ) were consistent with those estimated for healthy subjects using non-compartmental methods in Study 5 (geometric mean $115 \mathrm{pg} / \mathrm{mL}$ ) [12] following 200/25 $\mu \mathrm{g}$ FF/VI; a dose that did not have a significant effect on the QTc interval as measured by either QTcF or QTci. Furthermore, predicted VI $\mathrm{AUC}_{(0-24)}$ (geometric mean $408 \mathrm{pg} \cdot \mathrm{h} / \mathrm{mL}$ ) for Study 4 was notably lower than values estimated for healthy subjects using non-compartmental methods in Study 5 (geometric mean $775 \mathrm{pg} / \mathrm{mL}$ ) following 800/100 $\mu \mathrm{g}$ FF/VI which was well tolerated [12]. Potential inter-study variations in VI systemic exposure are, therefore, not considered to be a safety concern.

Despite the use of sensitive analytical methods (LLQ $10 \mathrm{pg} / \mathrm{ml}$ ), there was still a significant proportion of data below the LLQ for both FF and VI. The methodology that maximized the likelihood for all the data, treating those data below the LLQ as censored (M3 method) [20], was utilized for both analyses; since it has been reported in the literature, this method provides the most accurate and precise parameter estimates [9] and enabled robust modeling of the data and evaluation of potential covariates affecting the pharmacokinetics of FF and VI.

\section{Conclusion}

Integration of data from global safety and efficacy studies defined influential covariates on the pharmacokinetics of FF and VI in subjects with COPD. The population grouping defined as "race" was the only significant covariate identified to affect the pharmacokinetics of FF (CL/F). Significant demographic covariates identified to affect the pharmacokinetics of VI were age (on $\mathrm{CL} / F$ and $V_{1} / F$ ), bodyweight (on $\mathrm{CL} / F$ ), sex, and smoking (on $V_{1} / F$ ). The magnitude of the covariate effects on systemic exposure is not large enough to warrant FF/VI dosage adjustment in subjects with COPD.

Acknowledgments The author thanks the subjects and staff who participated in each of the studies. Bioanalytical support for the FF and VI analyses was provided by Worldwide Bioanalysis, Ware, Herts, UK. Editorial support in the form of copyediting was provided by David Cutler, PhD at Gardiner-Caldwell Communications (Macclesfield, UK) and was funded by GSK.

\section{Compliance with Ethical Standards}

Funding All of the studies used in this analysis were funded by GSK.

Conflict of interest Sarah Siederer and Shuying Yang are employed by and hold shares in GSK. Ann Allen was an employee of GSK at the time of these analyses.

Ethical approval All procedures were carried out in accordance with the International Conference on Harmonisation E6 guidelines for Good Clinical Practice and the principles of the Declaration of Helsinki. The studies described in this paper were approved by independent institutional review boards and ethics committees at all study sites. A full list of approving bodies is included in Appendix 1.

Informed consent Written informed consent was obtained from each subject prior to the performance of any study-specific procedures.

Open Access This article is distributed under the terms of the Creative Commons Attribution-NonCommercial 4.0 International License (http://creativecommons.org/licenses/by-nc/4.0/), which permits any noncommercial use, distribution, and reproduction in any medium, provided you give appropriate credit to the original author(s) and the source, provide a link to the Creative Commons license, and indicate if changes were made.

\section{Appendix 1: Independent ethics committees and institutional review boards providing study approval \\ Study 1}

Comité Etico Cientifico Servicio de Salud Valparaiso-San Antonio, Av. Brasil 1435, Valparaiso, Chile, 2362731.

Comité de Ética Científico Servicio Salud Araucanía Sur. Andrés Bello 636 Temuco, Chile.

Comité Etico Cientifico Servicio de Salud Metropolitano Oriente, Av. Salvador 364, Providencia, Santiago, Chile, 7500922.

Comité de Etica, Hospital Dipreca, Vital Apoquindo 1200, Las Condes, Santiago, Chile, 7601003.

Comité Etico Cientifico Servicio de Salud Metropolitano Oriente, Av. Salvador 364, Providencia, Chile, 7500922. 
Comité Etico Cientifico Servicio de Salud Metropolitano Sur Oriente, Av. Concha y Toro 3459, Puente Alto, Santiago, Chile, 8207257.

Comité Etico Cientifico Servicio de Salud Metropolitano Norte, San Jose 1053 Independencia, Santiago, Chile, 8380755 .

Comite de Etica de Investigacion en Seres Humans, Universidad de Chile, Facultad de Medicina, Independencia 1027, Santiago, Chile, 8380453.

Tallinn Medical Research Ethics Committee, National Institute for Health Development, Hiiu 42, Talliinn 11619 , Estonia.

Ethik-Kommission der, Aerztekammer Schleswig-Holstein, Bismarckallee 8-12, 23795 Bad Segeberg, Germany.

Institutional Review Board, Kishiwada City Hospital 1001, Gakuhara-cho, Kishiwada-City, Osaka, 596-8501, Japan.

Institutional Review Board, Medical Corporation Shintoukai Yokohama Minoru Clinic, 1-1-3-8, Besyo, Minamiku, Yokohama-shi, Kanagawa, 232-0064, Japan.

Nagata Hospital Institutional Review Board, 523-1, Shimormiyanaga-machi, Yanagawa-shi, Fukuoka, 832-0059, Japan.

Arima Kondou Kinen Medical Foundation Tomisaka Hospital Institutional Review Board, 5F, Sasaki Building, 2-5-7, Kishikawa, Bunkyo-ku, Tokyo, 112-0002, Japan.

Institutional Review Board, Kyushu Central Hospital of the Mutual Aid Association of Public School Teachers, 3-23-1, Shiobaru, Minami-ku, Fukuoka-shi, Fukuoka, 81 5-8588, Japan.

Arima Kondou Kinen Medical Foundation Tomisaka Hospital Institutional Review Board, 5F, Sasaki Building, 2-5-7, Kishikawa, Bunkyo-ku, Tokyo, 112-0002, Japan.

Institutional Review Board, Sakaide City Hospital, 6-43, Bunkyo-cho 1-chome, Sakaide-city, Kagawa, 762-0031, Japan.

Institutional Review Board, National Hospital Organization Ibarakihigashi National Hospital, 825 Terunuma, Tokai-mura, Naka-gun, Ibaraki, 319-1113, Japan.

Institutional Review Board, Medical Corporation-Junkokai Koto Hospital, 6-8-5, Ojima, Koto-ku, Tokyo, 136-0072, Japan.

Institutional Review Board, Nagano Prefectural Suzaka Hospital, 1332, Suzaka, Suzaka-city, Nagano, 382-0091, Japan.

Institutional Review Board, Iwata City, Hospital, 512-3, Okubo, Iwata-City Shizuoka 438-8550, Japan.

Institutional Review Board of Gachon Medical Center, 1198 Guwol-dong, Namdong-gu, Incheon, Korea, 405-760.

Hallym University Sacred Heart Hospital, 896, Pyeongchon-dong, Dongan-Gu, Anyang-Si, Gyeonggi-do, Korea, 431-070.
Institutional Review Board of The Catholic University of Korea, Uijeongbu St.Mary's Hospital, 65-1, Kumohdong, Uijeongbu-si, Kyonggi-do, Korea, 480-130.

Institutional Review Board of Korea University Anam Hospital, 126-1, Anam-Dong 5-ga, 136-705 Sungbuk-Ku, Seoul, Korea, 136-705.

Yeungnam University Medical Center IRB, 317-1 Daemyung-dong, Nam-gu Daegu, Korea, 705-717.

Institutional Review Board, St. Paul's Hospital, 620-56 Jeonnong-2dong, Dongdaemun-gu, Seoul, Korea, 130-848.

Institutional Review Board, Soonchunhyang University Bucheon Hospital, 1174 Jungdong, Wonmi-gu, Bucheonsi, Korea, 420-767.

Korea University Guro Hospital IRB, 80, Guro-dong, Guro-gu, Seoul, Korea, 152-703.

Wonju Christian Hospital, 162 Insan-dong Wonju-si, Kangwon-do, Korea, 220-701.

IRB of Konkuk University Hospital, 4-12, Hwayangdong, Gwangjin-gu, Seoul, Korea, 143-729.

Comité de Etica Cardiolink Clin Trials, Avenida Hidalgo 1813 A Poniente. Coloinia Obispado, Monterrey, Nuevo Leon, C.P, Mexico, 64060.

Comité de Etica del Instituto Jalisciense de Investigacion Clinica, S.A. de C.V., Penitenciaria 20 Colonia Centro, Guadalajara, Jalisco, C.P, Mexico, 44100.

Comité Bioetico para la Investigacion Clinica, S.C., Puebla 422-4, Col. Roma, Mexico D. F, C.P, Mexico, 06700.

Comité de Etica de la Facultad de Medicina de la UANL y Hospital Universitario "Dr Jose Eleuterio Gonzalez". Edificio de la Biblloteca Central de la Facultad de Medicina de la UANL Planta Baja, Av. Madero Poniente $\mathrm{s} / \mathrm{n}$ y Dr. E. Aguirre Pequeno, Colonia Mitras Centro, Monterrey, Nuevo León, Mexico, 64460.

Comité de Ethica e Investigacion de la Unidad de Investigacion clinica en medicina S. C, Av. La Clínica 2520 Int. 520, 522 y 524. Col. Sertoma, Monterrey, Nuevo León, Mexico, 64718.

Research and Ethics Committee, Veterans Memorial Medical Center, North Avenue, Quezon City, Philippines, 1101.

Institutional Ethics Committee, Mary Mediatrix Medical Center, J.P. Laurel Highway, Lipa City, Batangas, Philippines, 421.

Ethics Committee, St Paul's Hospital, General Luna Street, Iloilo City, Philippines, 5000.

Institutional Review Board, The Medical City, Ortigas Avenue, Pasig City, Philippines, 1600.

Ethics Committee, Lung Center of the Philippines, Quezon Avenue, Quezon City, Philippines, 1100.

Komisja Bloetyki Uniwersytetu Medycznego w Lodzi, Al. Kosciuszki 4, 90-419 Lodz, Polska. 
Ethics Committee under GOU VPO Russian State Medical University of Roszdrav, 1, Ostrovltianova Street, Moscow, 117997, Russian Federation.

Ethics Committee under GOU DPO State Educational Institution of Additional Professional Education Irkutsk State Institution of Postgraduate Physician Education of Roszdrav, 100, Microregion Yubileyniy, Irkutsk, 664079, Russia.

Board of Ethic under Minzdravsocrazvitiya of RF, 8 Petrovsky Boulevard, Moscow 127051, Russian Federation.

Ethics Committee under GUZ Center of Restorative Medicine and Rehabilitation \#2, 4 Dubinina Street Shakhty, Rostovskaya Region, 346510, Russia.

Ethics Committee under Yaroslavl Clinical Hospital \#2,

7, Yakovlevskaya Street, Yaroslavl, 150062, Russia.

Ethics Committee under MUZ City Hospital \#2, 6, Admiralskogo, Pyatigorsk, 357538, Russia.

Local Ethics Committee under State Educational Institution of the Highest Professional Education Ural State Medical Academy of Roszdrav 3 Repina Street, Ekaterinburg, 620219, Russian Federation.

Local Ethics Committee under MUZ City Hospital \#5, 75, Zmeinogorsky Track, Barnaul, 656045, Russia.

Ethics Committee under GOU VPO, Sibirsky State Medical University of Roszdrav, 2, Moskovsky Tract, Tomsk, 634050, Russia.

Ethics Committee attached to State Educational Institution of the Highest Professional Education Tumen State Medical Academy Roszdrav, 54, Odesskaya Street, Tumen, 625023, Russian Federation.

Expert Board for Biomedical Ethics for Clinical Disciplines under GOU VPO Bashkirsky State Medical University of Roszdrav, 3, Lesnaya Street, Ufa, 450077, Russia.

Ethics Committee of City Hospital \#17 GUZ ZAO of Moscow, 7, Building 1, Volynskaya Street, 119620, Moscow, Russia.

Local Ethics Committee under State Educational Institution of the Highest Professional Education Samara State Medical University Roszdrav, 89 Chapayevskaya Street, Samara 443099, Russia.

Schulman Associates Institutional Review, Board, Inc, 4290 Glendale-Milford Road, Cincinnati, Ohio 45242.

Western Institutional Review Board, 3535 7th Avenue SW, Olympia, Washington, 98502.

Miami VAHCS 2B199, 1201 NW 16th Street, Miami, Florida 33125.

Johns Hopkins Medicine Institutional Review Board, Office of Human Research, 1620 McEldarry Street, Reed Hall, Suite B-130, Baltimore, Maryland, 21205.

Research and Development Human Studies Subcommittee, 16111 Plummer Street (151), Sepulveda, California, 91343.

\section{Study 2}

Comité de Etica lndependiente en lnvestigacion Cllnica Dr.Carlos A. Barclay Larrea $13813^{\circ} \mathrm{A}, \mathrm{C} 1117 \mathrm{ABK}$ Ciudad Autonoma de Buenos Aires, Argentina.

Comité de Docencia e lnvestigacion Fundacion CIDEA, Billinghurst $16773^{\circ}$ Piso C1425DTG Ciudad Autonoma de Buenos Aires, Argentina.

Comité de Etica lndependiente en Investigacion Clinica, Larrea 13813A, C1117ABK Ciudad, Autonoma de Buenos Aires Argentina.

Comité de Docencia e lnvestigacion INSARES, M5500CCG Mendoza, Argentina.

Comité de Docencia e Investigacion CEMIT, Medicos Investigadores Tucuman, Cordoba 256, T4000DGFT, Tucuman, Argentina.

Comité de Etica en Investigacion Instiuto de Investigacoines Clinicas, Av. Colon 3364 PB, B7600FZN. Mar del Plata, Buenos Aires, Argentina.

Comité de Docencia e lnvestigacion de lnvesfigaciones en Patologias Respiratoilas Balcarce, 874, 4000, Tucuman, Argentina.

Comité de Docencia e lnvestigacion Ave Pulmo Carlos M. Alvear 3345 B7600FZN, Mar del Plata, Buenos Aires, Argentina.

Comité de Etica en lnvestigacion Instituto de lnvestigaciones Clinicas Av. Colon 3364 PB, Mar del Plata, Buenos Aires, Argentina.

Comité de Docencia e lnvestigacion lnstituto lnAER Arenales 3146, Piso 10 BC1425BEN Ciudad Aotonoma de Buenos Aires, Argentina.

Comité de Docencia e lnvestigacion Policlinico Modelo de Cipolletti San Martin y Libertad, R8324EMB Cipolletti, Rio Negro, Argentina.

Multicentricka Eticka Komise IKEM a FTNSP, Fakultni Thomayerova Nemocnices Poliklinikou, Videnska 800, 14059 Praha 4, Czech Republic.

Eticka Komise, Nemocnice Tabor, Kpt. Jarose 2000, 39019 Tabor, Czech Republic.

Eticka Komise, Vitkpvicke Nemocnice a.s., Zaluzanskeho 1192/15, 70384 Ostrava, Vitkovice, Czech Republic.

Eticka Komise FN Brno, Jihlavska 20, 62500 Brno, Czech Republic.

Eticka Komise Fakultni nemocnice Na Bulovce, Budinova 2, 18081 Praha 8, Czech Republic.

Ethik-Kommission der Aerztekammer Schleswig-Holstein, Bismarckallee 8, 223795, Bad Segeberg Germany.

National Hospital Organzsation Headquarters, Central Institutional Review Board, 152-0021, Higashigaoka, Meguro -ku-, Tokyo, 152-8621, Japan.

Asamoto Naika Lin Institutional Review Board, Haimuwisutaria Building. 1F, 1, Fukakusahotta-cho, Fushimi-ku, Kyoto-city, Kyoto, 612-0026, Japan. 
Institutional Review Board of Japanese Red Cross Kyoto Diani Hospital, 355-5, Haruobicho, Kamanzadori, Marutamachi, Agaru, Kamigyo-ku, Kyoto city, Kyoto, 602-8026, Japan.

National Hospital Organization Central Review Board 2-5-21 Higashigaoka, Meguro-ku, 152-0021, Japan.

National Hospital Organization Headquarters Central Review Board, 2-5-21, Higashigaoka, Meguro-ku,1520021, Tokyo.

Social Medical Corporation Keiaikai Nakagami Hospital, Institutional Review Board 6-25-5, Chibana, OkinawaCity, Okinawa, 904-2195, Japan.

Institutional Review Board of Kameda General Hospital, 929 Higashicho, Kamogawa-city, Chiba, Japan.

Medicaline Corporation Shinkenkai Suzuki Internal Medicine Cardiovascular Medicine, Institutional Review Board 202, Maison de Statue 1-39-5, Sangenjaya, Setagaya-Ku, Tokyo, 154-0024, Japan.

AMC Nishi-umeda Clinic Institutional Review Board, 3-3-45, Umeda, Kita-ku, Osaka-City, Osaka 530-0001 Japan.

Social Medical Corporation Keiaikai Nakagami Hospital, Institutional Review Board, 6-25-5, Chibana, OkinawaCity, Okinawa, 904-2195, Japan.

Institutional Review Board, Ibaraki Seinan Medical Center Hospital, 2190, Sakai-cho, Sashima-gun, Ibaraki, 306-0433, Japan.

National Hospital Organization Central Review Board 2-521, Higashigaoka, Meguro-ku, Tokyo, 152-0021, Japan.

Komisja Bioetyczna przy Instytucie Gruzlicy I Chorob Pluc ul. Plocka 26, 01-138, Warszawa, Polska.

National Drug Agency, 48 Aviator Sanatescu Street, District 1, 011478, Bucharest, Romania.

National Ethics Committee, 48 Aviator Sanatescu Street, District 1, 011478, Bucharest, Romania.

Ethics Committee under Federal Service on Surveillance in Healthcare and Social Development, Petrovskiy Bulvar, 8, Str. 2, Moscow, 127051, Russian Federation.

Ethics Committee attached to FGU Scientific Research Institute of Pulmonology, 32/61, 11-Parkovaya Street, Moscow, 105077, Russian Federation.

Ethics Committee attached to State Educational Institution of the Highest Professional Education Krasnoyarsk State Medical University named after Prof. V.F.VojnoJasenetskiy of Minzdravsocrazvitya of Russia, 1, Partizana Zheleznyaka Street, Krasnoyarsk, 660022, Russian Federation.

Ethics Committee attached to City Polyclinic \#94, 24, Tovarishcheskiy Prospect, Saint-Petersburg 193231 Russian Federation.

Local Ethics Committee attached to Kazan Research Institute of Epidemiology and Microbiology, 67, Bolshaya Krasnaya ul. Kazan, 420015, Russian Federation.
Local Independent Ethics Committee attached to State Educational Institution of the Postgraduate Professional Education Ural State Medical Academy of Postgraduate Education, 51 Molodogvardeycev Street, Chelyabinsk, 454136, Russian Federation.

Ethics Committee attached to State Educational Institution of the Highest Professional Education Moscow Medical Academy named after I.M Sechenov of Roszdrav, 8, Trubetskaya Street, Building 2, 119991, Moscow, Russian Federation.

Ethics Committee attached to Clinical Hospital \#2, d. 24, Ul. Popova. Yaroslavl, 150010, Russian Federation.

Ethics Committee attached to Ivanovo State Medical Academy, 8, Friedrich Engels Prospect, Ivanovo, 153012, Russian Federation.

Ethics Committee attached to St. George the Martyr City Hospital, 1, Sevemy Pr., Saint-Petersburg, 194354 Russian Federation.

Ethics Committee attached to City Clinical Hospital \#3, 22, Ostrovskogo Street, Kemerovo, 650099 Russian Federation.

Ethics Committee attached to City Consultative Diagnostic Center \#1, 10, Sikeyrosa Street, Saint-Petersburg, 194354, Russian Federation.

Ethics Committee attached to City Clinical Hospital \# 11, 6, Dvintsev Street, Moscow, 127018, Russian Federation.

Central Ethics Committee, Ministry of Health of Ukraine 5, Narodnogo Opolchennya Street, 03151 Kyiv, Ukraine.

Local Ethics Committee, Kharkiv City Hospital \#13, 137 Gagarina Street, 61035, Kharkiv, Ukraine.

Local Ethics Committee Institute of Phthisiatry and Pulmonology, 10, Amosova Street, 03680, Kiev, Ukraine.

Local Ethics Committee Research Institute of Gerontology 67, Vyshgorodskaya Street, 01114, Kyiv, Ukraine.

Local Ethics Committee Kyiv City Tuberculosis Hospital \# 1, 121/3, Kharkivskeshosse, 02091, Kyiv, Ukraine.

Local Ethics Committee, City Clinical Hospital \#6, 13 Batumska Street, 49051, Dnipropetrovsk, Ukraine.

Local Ethics Committee Odesa Regional Clinical Hospital, 26 Zabolotnogo Street, 65117, Odesa, Ukraine.

Local Ethics Committee, Research Center of Radiation Medicine, 119/121 Peremogy Avenue, Kyiv, 04050, Ukraine.

Local Ethics Committee Simferopol Railroad Hospital, 142 Kyivska Street, 95043, Simferopol, Ukraine.

Schulman Associates IRB, Inc. 4290 Glendale-Milford Road. Cincinnati, Ohio, 45242, USA.

Palmetto Health Institutional Review Boards, Research Administration, 5 Medical Park, Columbia, South Carolina, 29203, USA. 
Birmingham VA Institutional Review Board, Department of Veterans Affairs Medical Center, 700 South 19' th Streets, Birmingham, Alabama, 35233, USA.

Human Studies Subcommittee, Bay Pines VA Healthcare System, Research and Development Service (151), 10000 Bay pines Blvd, Bay Pines, Florida, 33744, USA.

Scott \& White Institutional Review Board, 2401 South 31st Street, Temple, Texas 76508, USA.

\section{Study 3}

Chesapeake Research Review 7063 Columbia Gateway Drive, Suite 110, Columbia, MD 21046, USA.

\section{Study 4}

Regional Komite for Medisinsk og Helsefaglig Forskningsetikk, Nord-Norge, (REK Nord) Universitetet i Troms $\varnothing$, Det Medisinske Fakultet.9037 Troms $\varnothing$. Norway.

Regionala Etikprövningsnämnden i Göteborg Medicinargatan 3, Plan 5, SE-413 90, Göteborg, Sweden.

\section{References}

1. Claxton AJ, Cramer J, Pierce C. A systematic review of the associations between dose regimens and medical compliance. Clin Ther. 2001;23:1296-310.

2. Boscia JA, Pudi KK, Zvarich MT, Sanford L, Siederer SK, Crim C. Effect of once daily fluticasone furoate/vilanterol on $24 \mathrm{~h}$ pulmonary function in patients with chronic obstructive pulmonary disease: a randomized, three-way, incomplete block, cross-over study. Clin Ther. 2012;34:1656-66. doi:10.1016/j. clinthera.2012.06.005.

3. Lötvall J, Bakke PS, Bjermer L, Steinshamn S, Scott-Wilson C, Crim C, Sanford L, Haumann B. Efficacy and safety of 4 weeks' treatment with combined fluticasone furoate/vilanterol in a single inhaler given once daily in COPD: a placebo-controlled randomised trial. BMJ Open. 2012;2:e00370. doi:10.1136/ bmjopen-2011-000370.

4. Thorsson L, Dahlstrom K, Edsbacker S, Kallen A, Paulson J, Wiren J-E. Pharmacokinetics and systemic effects of inhaled fluticasone propionate in healthy subjects. Br J Clin Pharmacol. 1997;43:155-61.

5. Bernstein DI, Allen DB. Evaluation of tests of hypothalamicpituitary-adrenal axis function used to measure effects of inhaled corticosteroids. Ann Allergy Asthma Immunol. 2007;98:118-27.

6. Salpeter SR, Ormiston TM, Salpeter EE. Cardiovascular effects of beta-agonists in patients with asthma and COPD: a metaanalysis. Chest. 2004;125:2309-21.
7. McKeage K. Fluticasone furoate/vilanterol: a review of its use in chronic obstructive pulmonary disease. Drugs. 2014;74:1509-22. doi:10.1007/s40265-014-0269-6.

8. Kempsford R, Allen A, Bareille P, Bishop H, Hamilton M, Cheesbrough A. The safety, tolerability, pharmacodynamics and pharmacokinetics of inhaled fluticasone furoate (FF) and vilanterol (VI) are unaffected by administration in combination. Eur Respir J. 2011;38(Suppl. 55):138s.

9. Ahn JE, Karlsson MO, Dunne A, Ludden TM. Likelihood based approaches to handling data below the quantification limit using NONMEM vilanterol. J Pharmacokinet Pharmacodyn. 2008;35:401-21. doi:10.1007/s10928-008-9094-4.

10. Kerwin EM, Scott-Wilson C, Sanford L, Rennard SI, Agusti A, Barnes N, Crim C. A randomised trial of fluticasone furoate/ vilanterol $(50 / 25 \mu \mathrm{g} ; 100 / 25 \mu \mathrm{g})$ on lung function in COPD. Respir Med. 2013;107(4):560-9.

11. Martinez FJ, Boscia J, Feldman G, Scott-Wilson C, Kilbride S, Fabbri L, Crim C, Calverley PMA. Fluticasone furoate/vilanterol $(100 / 25 ; 200 / 25 \mu \mathrm{g})$ improves lung function in COPD: a randomised trial. Respir Med. 2013;107(4):550-9.

12. Kempsford R, Allen A, Kelly K, Saggu P, Crim C. A repeat-dose thorough QT study of inhaled fluticasone furoate (FF)/vilanterol (VI) combination in healthy subjects. Br J Clin Pharmacol. 2013;77:466-79. doi:10.1111/bcp.12243.

13. R Development Core Team. R: a language and environment for statistical computing. 2008. R Foundation for Statistical Computing, Vienna, Austria. http://www.R-project.org. Accessed 4 Dec 2013.

14. Beal S, Sheiner LB, Boeckmann A, Bauer RJ. NONMEM user's guides. 2009. Icon Development Solutions, Ellicott City, MD.

15. Jonsson EN, Karlsson MO. Xpose-an S-PLUS based population pharmacokinetic/pharmacodynamic model building aid for NONMEM. Comput Methods Programs Biomed. 1999;58:51-64.

16. Post TM, Freijer JI, Ploeger BA, Danhof M. Extensions to the visual predictive check to facilitate model performance evaluation. J Pharmacokinet Pharmacodyn. 2008;35:185-202. doi:10. 1007/s10928-007-9081-1.

17. Allen A, Bal J, Cheesbrough A, Hamilton M, Kempsford R. Pharmacokinetics and pharmacodynamics of intravenous and inhaled fluticasone furoate in healthy Caucasian and East Asian subjects. Br J Clin Pharmacol. 2014;77:808-20. doi:10.1111/bcp. 12263.

18. Allen A. The relationship between fluticasone furoate systemic exposure and cortisol suppression. Clin Pharmakinetics. 2013;52:885-9. doi:10.1007/s40262-013-0078-1.

19. Allen A, Davis A, Hardes K, Tombs L, Kempsford R. Influence of renal and hepatic impairment on the pharmacokinetic and pharmacodynamic properties and tolerability of fluticasone furoate and vilanterol in combination. Clin Ther. 2012;34:2316-32. doi:10.1016/j.clinthera.2012.11.001.

20. Beal SL. Ways to fit a PK model with some data below the quantification limit. J Pharmacokinet Pharmacodyn. 2001;28:481-504. 